\title{
DIÁRIO DE ILHÉUS: OS TEXTOS LITERÁRIOS DA DÉCADA DE 30
}

\author{
Antonio Santos Barreto* \\ Humberto Hermenegildo Araujo** \\ Universidade Federal do Rio Grande do Norte
}

Resumo: No início do século passado os jornais eram os maiores divulgadores da Literatura no Brasil, uma vez que, os livros eram escassos, custavam muito caro e não chegavam às regiões periféricas do país. Assim, existe a necessidade de se preservar os jornais e periódicos do início do século XX, visto que, esses nem sempre são preservados de forma adequada e conveniente. Uma exceção a essa realidade são os jornais dos grandes centros como a Folha de São Paulo que tem experiências bem sucedidas sobre a preservação das publicações literárias em suas edições antigas. Por outro lado, jornais como o Diário da Tarde de Ilhéus, que guardam em suas páginas um riquíssimo acervo histórico e literário, estão se deteriorando por falta de espaço e conservação adequada, mesmo sendo um acervo importante para a preservação da Memória Literária do Sul da Bahia.

Palavras-chave: Jornais. Periódicos. Literatura. Memória. Diário.

\section{Diário de Ilhéus, um construtor da identidade local}

Estudos recentes no Brasil têm revelado a valorização de temas da história local e regional, tradicionalmente desprestigiados diante de uma perspectiva globalizante, situação essa que passou a ser invertida na segunda metade do século XX, com a realização de pesquisas amplamente amparadas em farta documentação. Contrariamente, embora esse interesse pela história local tenha assumido novas características, isso não correspondeu a uma valorização desse patrimônio coletivo construído ao longo dos anos e de sucessivas gerações, a despeito da ampliação gradativa de espaços institucionais destinados à preservação do patrimônio documental no país.

As possibilidades de pesquisa, a partir das fontes documentais produzidas por órgãos

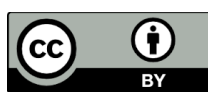

Esta obra está licenciada sob uma Creative Commons - Atribuição 4.0

\footnotetext{
* Doutorando do Programa de Pós-Graduação em Estudos da Linguagem da Universidade Federal do Rio Grande do Norte. E-mail: kinhobarreto@bol.com.br.

** Professor pós-doutor em Teoria Literária e Literatura Comparada, FFLCH/USP. Orientador do Programa de Pós-Graduação da Universidade Federal do Rio Grande do Norte. E-mail: hharauj@gmaill.com.
} 
da administração pública ou de centros de documentação de universidades como a UESC ${ }^{1}$, são bastante extensas. No que diz respeito à história da região do cacau, especialmente Ilhéus que é a mais antiga cidade da região, a análise de temas vinculados aos domínios da política, economia, sociedade e cultura revela a dinâmica das áreas do interior que, muitas vezes, são desprezadas nas investigações da história do estado, circunscritas apenas ao recôncavo e à capital. Tais estudos demonstram que, longe de existir uma uniformização dos processos históricos, as singularidades permitem aflorar a complexidade das sociedades humanas.

É através da contribuição da memória das sociedades que se constituem as identidades sociais que são baseadas e solidificadas pelo compartilhamento das experiências coletivas. Os documentos históricos que tratam da vida social, religiosa, política, econômica e literária dessas regiões apresentam-se como uma das formas de visualização dessas experiências e memórias. Com tal suporte, é possível socializar e democratizar a informação a respeito do passado e das experiências comuns que permitiram à sociedade suas representações atuais. Neste caso, se na Ilhéus de hoje não fosse possível encontrar as marcas deixadas pelos habitantes de outras épocas, a cidade jamais poderia ser considerada um corpo social centenário que guarda em si uma história na qual as marcas dos índios tupinambás e aimorés, dos jesuítas, dos portugueses, dos turcos e dos negros que aí viveram são visíveis no seu patrimônio cultural, arquitetônico e cultural.

Le Goff (1996a) afirma que a memória expressa noções que se remetem mutuamente ao tempo e espaço, suporte e sentido, memória individual e coletiva, tradição e projeto, acaso e intenção, esquecimento e lembrança, bem como as diferenças de natureza entre sociedades com escrita ou não, influindo, assim, na construção social da memória. Ele também afirma que há diferentes memórias ao longo da história e que estas servem como fonte de identidade individual de uma sociedade. A memória, segundo ele, é vista como objeto de luta das forças sociais pelo poder.

Para Nora (1993a, p. 15), a memória verdadeira, transformada por sua passagem em história, dá lugar a uma memória arquivista, ou seja, “[...] à constituição vertiginosa e gigantesca do estoque material daquilo que nos é impossível lembrar”. Neste quadro, há lugares para esta memória, ou seja, não há mais o contexto histórico conforme o calor dos acontecimentos, no ato próprio de sua ocorrência imediata. Assim, estes lugares de memória são simultaneamente materiais, como o jornal Diário da Tarde, simbólicos e funcionais.

\footnotetext{
${ }^{1}$ A Universidade Estadual de Santa Cruz está localizada no eixo Ilhéus-Itabuna e mantém o CEDOC - Centro de Documentação e Memória Regional, que se responsabiliza pelo arquivo e documentação de alguns dos principais jornais da região cacaueira do início do século XX e, dentre eles, está o Diário da Tarde.
} 
Procuram escapar da história, sendo sua razão fundamental parar o tempo, bloquear o trabalho de esquecimento, fixar um estado de coisas. Ainda segundo Pierre Nora, em uma sociedade marcada pelo "produtivismo arquivístico", o vestígio é sacralizado, constituindo-se o arquivo “[...] como a secreção voluntária e organizada de uma memória perdida, mas não o saldo mais ou menos intencional de uma memória vivida”. (NORA, 1993b, p. 15).

A memória, ao contrário da história, não seria um conhecimento intencionalmente produzido. É subjetiva e, como tal, uma forma de se reconfigurar um passado, transmissor de experiência, simultaneamente seguro e dúbio. Sua primeira função não é preservar o passado, mas adaptá-lo, enriquecendo e manejando o presente, não se constituindo, portanto, em uma reflexão pronta do passado, mas reconstruções seletivas e ecléticas baseadas em ações subsequentes, percepções e códigos maleáveis pelos quais nós delineamos, simbolizamos e classificamos o mundo.

Le Goff (1996b) menciona os documentos e monumentos como materiais da memória coletiva, diferenciando-os em função de suas características. Assim, os monumentos apresentam atributos que são heranças do passado e, ao mesmo tempo em que evocam o passado, liga-os ao poder de perpetuação voluntária ou involuntária das sociedades históricas, apresentando uma intencionalidade.

De acordo com as concepções apresentadas até este ponto, o arquivo e a memória estão sempre muito próximos, pois o primeiro constitui a memória de uma organização, qualquer que seja a sociedade, uma coletividade, uma empresa ou uma instituição e, ao mesmo tempo em que garante a memória é por ela garantido. A principal razão para eles existirem é a necessidade de uma memória registrada. Para isso acontecer é preciso que os arquivistas contem com o apoio de historiadores para, juntos, trabalharem a definição de arquivos como lugares de elaboração e de conservação da memória coletiva.

O jornal de Ilhéus pode ser inserido como lugar de memória e arquivo, não porque seja considerado melhor ou pior do que outras fontes que guardam os documentos, fatos e acontecimentos de uma dada época, região ou sociedade, mas, porque eles, segundo Nora (1993) complicam o simples exercício da memória com um jogo de interrogação sobre a própria memória. Segundo o historiador, os jornais, independentemente do valor desigual dos textos, têm suas constantes e suas especificidades, implicando num saber de outras memórias, num desdobramento do homem de escrita e do homem de ação, na identificação de um discurso individual ou coletivo, na inserção de uma razão particular ou de Estado. Esses motivos fazem dos jornais guardiães da memória local, regional ou nacional e, por isso, eles 
podem ser considerados lugares de memória.

\title{
As publicações do Diário da Tarde: um arquivo permanente.
}

As notícias e os textos literários publicados nas páginas do Diário da Tarde, na década de trinta do século XX, inserem o jornal neste lugar de memória e arquivo, porque retrata os fatos, acontecimentos e relatos de uma época rica da região do cacau no sul da Bahia. Riqueza essa sustentada pelos frutos de ouro do cacau que tão bem se adaptou ao clima e solo baianos e, ainda nos dias atuais, servem com marca de uma região que foi rica e promissora, a que mais pagava imposto para o Estado da Bahia, posto esse que só veio a perder para o Polo Petroquímico de Camaçari.

Os textos veiculados demonstram os acontecimentos e preocupações do jornal com situações que tocam de perto as dores, os sofrimentos e a condição da vida humana, como a matéria da edição de número 1.503 de 06 de Abril de 1933, publicada na primeira página com mais de uma chamada, que trata da chegada de imigrantes a Ilhéus, em fuga da seca e da pobreza de outras regiões, principalmente, do sertão de Sergipe:

\begin{abstract}
As dores dos flagelados
Fugindo dos quadros terríveis da seca e encontrando sofrimentos peores ${ }^{2}$

Mais uma leva de infelizes nordestinos chegou hontem à cidade

O princípio de solidariedade humana é muito forte, mas não justifica absolutamente o silêncio da imprensa em face das remessas subseqüentes e numerosas de flagelados para essa zona, onde eles chegam, conduzindo o fardo atroz de suas dores e das suas humilhações, nos navios da Baiana, nas barcaças, em quase todos os meios de transporte marítimos que possam conduzi-los da capital para esta cidade. Ilhéus tornou-se assim, há algum tempo, o centro de convergência das levas de desamparados que aqui chegam atraídos pela fama de riquesa da terra, convertida para eles numa Canaan afortunada, quando vista à distância, ignorando todos que as condições atuais desta região já não favorece muito aos que vêm de longe procurar trabalho a subsistência que lhes faltaram nos sertões, varridos pelo acoite terrível da soalheira impiedosa.

Ainda hontem pelo vapor "Canavieiras" chegou uma nova leva de flagelados. Assistimos o seu desembarcar que, confrangeu-nos o coração os aspectos daquela miséria coletiva, a desgraça nua e crua daquela gente humilde que desfilava, como um bando de vencidos, entre as alas dos curiosos, alguns apiedados, outros indiferentes, não raro achando divertido o espetáculo...

Vimos famílias numerosas, homens, mulheres, creanças, algumas ainda de peito, todos revelando na fisionomia triste, abatida, macilenta, os vestígios dessa jornada de sofrimento para a terra da promissão.

E é aqui essa terra. Trazem para aqui um punhado de esperanças. Vêm iludidos com a perspectiva enganosa de encontrar fortuna, começar nova vida, esperando dais
\end{abstract}

\footnotetext{
${ }^{2}$ Os textos coletados do jornal serão transcritos com a ortografia da época, ou seja, do início do século XX e fazem parte do corpus do projeto de pesquisa; MEMÓRIA E FICÇÃO: As publicações literárias do jornal Diário da Tarde - Ilhéus, como construto de memória da Região do Cacau, em desenvolvimento como projeto de doutorado junto ao Programa de Pós-Graduação em Estudos da Linguagem da UFRN, na área de concentração em Literatura Comparada.
} 
melhores, mais propicio, ao acesso fácil da prosperidade.

Mas bem depressa encontram decepções amargas e verificam que se pode bem morrer de fome na terra prometida. O número de vítimas da seca que aporta a esta zona é considerável e a concentração dos infelizes sertanejos aqui têm contribuído para dificultar a tarefa da sua subsistência e manutenção dos nossos pobres irmãos do nordeste assolado pela seca.

Depois entre os que chegam fugindo ao flagelo mais de um terço é de creanças, velhos, mulheres e doentes, incapazes, portanto para o trabalho. Alguns mal resistem aos abalos de uma viagem, penosa sem conforto, acidentada. Inúmeros têm morrido nessa jornada cruel. Privações, padecimentos, moléstias, todos os horrores conhecem esses mártires anônimos, obscuros, ignorados. Não poucos sucumbem ao desamparo. Mas eles continuam chegando, às levas, aos punhados, às dezenas e às centenas, para conhecer, finalmente, que por La os quadros da seca são terríveis, mas, além desses quadros, há sofrimentos peores. (DIÁRIO $\mathrm{n}^{\mathrm{o}} 1.503 \mathrm{de}$ 06/04/1933).

Matérias registradas nas páginas do jornal como As dores dos flagelados, podem ser consideradas como uma memória resgatável e faz do jornal um arquivo, uma fonte de documentos, no qual está inserida a vida política, econômica, social, religiosa e literária da região do cacau no início do século XX, além de nos levar a considerar que uma ideologia, por parte da classe dominante, é veiculada na mesma, uma vez que a carga de conceitos negativos, que consta, inclusive em um dos subtítulos da matéria, sobre os retirantes que chegavam à região tida como terra da promessa e da fortuna é bastante visível. Ora, se a memória registrada não é um resultado estático, mas um processo que serve às exigências de instituições, estados, organizações, estudiosos etc., ela está sempre à procura desse sentido que a liga às instituições, estados, organizações e estudiosos. Portanto, a memória registrada midiatiza a reflexão derivada do pensamento organizacional e institucional para analisar uma situação, assegurando decisões que sustentam a ação e orientam o desenvolvimento das operações.

Nora (1993c, p. 27) afirma que os lugares de memória, diferentemente de todos os objetos de história, não têm referentes na realidade, pois, eles mesmos são seu próprio referente, são lugares duplos, lugares de excesso, fechados sobre si mesmo, fechados sobre sua própria identidade e, recolhidos sobre seu próprio nome, mas ao mesmo tempo eles estão abertos à extensão de suas significações.

Para Barbosa (2007), o estudo dos jornais desde o século XIX nos interessa porque neles é possível encontrar textos que, sejam profanos ou canônicos, literários ou sem qualidade, despertam nas pessoas a curiosidade pela leitura. Portanto, é através dos jornais que traçamos o perfil do leitor e da memória de um dado momento de nossa história. Ela afirma que:

É desta perspectiva, portanto, que o jornal interessa-nos: ele é parte da economia interna da linguagem, da divulgação e da circulação do literário no século XIX. 
Nesse sentido, se não o tomamos mais só como arquivo, acervo de textos, interessam todos os jornais, ou os mais variados jornais, e não apenas aqueles consagrados pela participação de autores célebres. (BARBOSA, 2007, p. 38).

É partindo dessa significação que o Diário da Tarde pode ser inserido na noção de arquivo permanente, pois traz em seu bojo a perspectiva de que expressa um tipo de memória materializada. Como tal, esta memória confunde-se com o próprio arquivo a ser preservado. No Diário é possível encontrar um conjunto de documentos de valor histórico/cultural, como as publicações de prestações de contas da prefeitura e da recebedoria de rendas do estado. Esses documentos são probatórios, informativos e devem ser definitivamente preservados. Os documentos históricos têm valor permanente e são constituídos por livros, papéis, mapas, fotografias, monumentos ou qualquer espécie de elemento informativo, independente de sua forma ou características físicas.

Os arquivos são práticas de identidade, memória viva, processo cultural indispensável ao funcionamento no presente e no futuro. No Jornal ilheense isso pode ser constatado a partir das publicações de crônicas, contos, poesias, notas de nascimento, aniversários, conclusão de cursos, falecimentos, aulas de Francês, cursos de corte costura, notícias da região, do estado, do país, do mundo ou assuntos que tratam do cotidiano das pessoas.

Por conta da pouca importância ou relevância que tinham os arquivos públicos e privados no Brasil, incluindo aí os jornais, em especial os do século XIX e XX, até bem pouco tempo nada, ou quase nada, se podia fazer por esses patrimônios de valor documental, mas, a partir do momento em que os mesmos foram institucionalizados como resultado de um processo de independência e formação dos estados, passou-se então a considerar estas instituições como arquivos históricos e, portanto, repositórios de uma memória tida como forjadora da identidade local, regional e nacional. Como condição inerente à escolha do que será preservado como arquivo de valor histórico, a avaliação de documentos se expressa, na literatura sobre o tema, como um aparato dotado de racionalidade técnica, referido - nem sempre explicitamente - à função política da memória e do patrimônio por parte do Estado e da iniciativa privada.

Para Foucault (2002, p. 148-149), os arquivos são importantes porque fazem com que tantas coisas ditas sejam trazidas à tona, fazendo surgir os assuntos, acontecimentos e fatos que os homens fizeram ou disseram há tantos anos, não segundo as leis do pensamento, ou segundo o jogo das circunstâncias, mas, segundo a necessidade de se estudar, vivenciar ou rememorar os acontecimentos de uma dada época ou sociedade. Para ele, o arquivo é sim 
aquilo que se justifica, sem que se saiba a razão imediata do que pode ser dito num dado sistema de discursividade. Arquivo, segundo o autor, é o que dá sentido ao que é dito, já que ele é a lei do que pode ser dito, o sistema que rege o aparecimento dos enunciados como acontecimentos singulares.

Esse sentido sobre o que é dito pode ser percebido quando se busca nas páginas do Diário a vida social do país e da cidade de Ilhéus, do início do século passado. Analisando esses acontecimentos, é possível perceber a importância que é dada aos eventos que tratavam da chegada de artistas famosos ao Brasil, bem como a divulgação de filmes que iriam ser apresentados no Cine Teatro de Ilhéos ${ }^{3}$. Essa importância só pode ser percebida a partir da busca de informações contidas no jornal que retratam como as pessoas se preparavam para tais acontecimentos e como estes eram importantes para aquelas que tinham posição social privilegiada:

\begin{abstract}
Possuída
A imprensa mundial proclama, aos quatro ventos que esse filme é uma verdadeira obra d'arte. É falado, muzicado e sicncronizado. JOAN CRAWFORD a insuperável, é a principal figura; CLARK GABLE, o galã. Possuída será exibido nas soirées de hoje e de amanhã no elegante e confortável CINE TEATRO DE ILHÉOS. (DIÁRIO no ${ }^{\circ} 1.507$ de 07/04/1933, p. 4)
\end{abstract}

A nota sobre a divulgação do filme "Possuída", revela também que a vida social da cidade era divulgada para os moradores de outras cidades da região do cacau, uma vez que o jornal mantinha um bom número de assinantes que o recebiam através da rede ferroviária que administrava a linha férrea em funcionamento na região até o ano de 1958.

Outra característica do Diário de Ilhéus é que as publicações, sejam elas de acontecimentos da região ou de textos literários, na maioria das vezes, têm autores que assinam o texto ou a reportagem com pseudônimos, prática que os jornais já utilizavam desde o século XIX. Para Barbosa (2007), essa é uma prática que vem desde o surgimento dos primeiros jornais na Colônia e, essa tendência ao anonimato, ou seja, o uso do pseudônimo, se dava tanto nos jornais da corte como naqueles que estavam nas províncias.

Por conta de uma tendência ao desaparecimento e de uma possibilidade de ser sempre levado ao esquecimento é que os documentos de valor histórico necessitam dos arquivos que, por sua vez, também estão condenados ao desaparecimento e ao esquecimento. Segundo Derrida (2001), não haveria certamente o desejo de arquivo se as publicações e os documentos guardados neles não estivessem condenados ao desaparecimento e ao esquecimento.

\footnotetext{
${ }^{3}$ A palavra Ilhéus e grafada na forma Ilhéos em várias publicações do jornal.
} 
Para Janice Theodoro (1998), grande parte da memória histórica corresponde à ausência das perdas, exclusões e tudo que não está registrado pode não fazer parte da memória ou da narrativa tradicional. Assim, segundo a autora, quando pretendemos ou aceitamos o desafio de trabalharmos com a preservação da memória da nossa região, cidade, país ou até mesmo as nossas memórias, devemos lembrar que memória e esquecimento são pares inseparáveis e, portanto, correlatos. Só há lembranças porque há esquecimento.

Nas páginas do Diário, do início do século passado, estão registradas uma parte importante da história do povo de Ilhéus e região, pois a partir delas é possível observar aspectos histórico-sociais relevantes e gerais de uma sociedade que se constrói no Brasil dessa época e, que não pode ser relegada ao esquecimento.

\section{As publicações literárias do Diário}

Ainda que todo o jornal seja um conjunto de elementos simbólicos, parte dele trata de aspectos materiais, econômicos e instrumentais, algo próximo da noção de civilização, ou seja, são elementos comuns a todos os jornais e implicam a dimensão material, técnica e objetiva. Desse modo, o jornal pode se aproximar da noção de cultura ao expressar valores, ideias e modos profundos de ser de um povo. Em tal perspectiva, os cadernos culturais podem trazer a marca de um grupo social, suas realizações subjetivas, suas concepções acerca da política, da religião, dos festejos locais, das mudanças que ocorrem na sociedade, ou seja, de todos os acontecimentos da comunidade em que ele está inserido, do país e do mundo.

Para Meyer (1996a), os jornais desde o século XIX traziam em suas seções novidades que despertavam o gosto de seus assinantes e das pessoas que os compravam com certa regularidade e, essas novidades eram compostas de anúncios, traduções de romances folhetins da língua francesa, textos literários publicados por autores conhecidos ou que usavam o pseudônimo para prender o público, ou seja, os jornais já usavam de truques publicitários para prender seus leitores. Segundo a autora jornais como O Jornal do Comércio, "Edição de São Paulo", são os primeiros divulgadores da Semana de Arte Moderna de 22. 'Já em 3 de janeiro de 1922 o jornal divulga amplamente na sua seção 'Registros' a Semana de Arte Moderna a se realizar”. (MEYER, 1996b, p. 363).

Dentro desta perspectiva os suplementos literários e as colunas literárias de jornais, do início do século XX, como o Diário da Tarde, tem em suas páginas a preocupação de mostrar que em uma região periférica do sul da Bahia, nas décadas de 20 e 30 já se dava lugar às publicações literárias em um suplemento ou em colunas literárias como "Conto da Semana“, "Vesperal" e "Cosmorama". Este suplemento e colunas se inserem como suporte do 
jornal para abarcar uma parte deste que é direcionada para os textos literários, em sua grande maioria crônicas, contos e poesias. Cabe esclarecer, ainda, que o tema do jornalismo cultural sempre remete a pares de conceitos opostos ou suas combinações, como elite e massa, tradição e modernidade, erudição e vulgarização, como exposto nos textos literários a seguir, como uma amostragem do material coletado por esta pesquisa.

\author{
Os meus versos de amor \\ Elle dirá, lisant \\ Ces vers tout simpels dele: \\ "Quile est done cette fémine? \\ Et me compreenda pas! \\ Fiz uns versos de amor. Fi-los \\ No meu segredo co'a penna da \\ Emoção e a tinta da saudade, \\ Bendizendo, Maria, o teu nome, \\ Em segredo. \\ E esses versos? Rasguei-os. Não \\ Eram dignos de ti. O meu verso \\ Melhor foi o que eu não escrevi... (DIÁRIO, n. 846 de 10/01/1931, p. 2) \\ O poema seguinte, do mesmo autor, tem uma estrutura bem diferente:
}

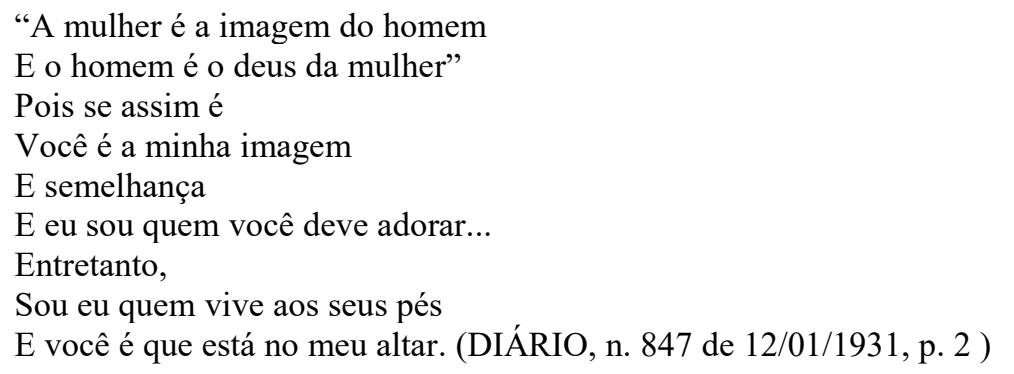

Esses poemas publicados na Coluna literária "Cosmorama", o primeiro com o título de Os meus versos de amor, e o segundo sem título, são escritos por um autor que usa o pseudônimo de Lívio, coisa muito comum para esse início de século, pois, muitas vezes, os escritores e poetas não se identificavam por medo de pressões políticas ou religiosas. Do ponto de vista formal, eles demonstram que boa parte dos poemas publicados tinha característica da poesia moderna, uma vez que fogem aos padrões de métrica, rima, estrofe, estrutura, além de as estrofes do primeiro poema serem uma mistura de Francês com Português. Já o poema a seguir expande elementos percebidos nesta discussão:

\title{
Uma perfeição
}

Que coisa interessante:

Quando eu gostava dela.

Vivia, a todo instante 


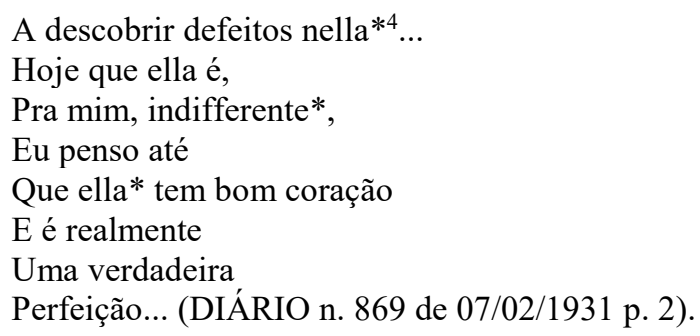

É possível observar a beleza estética do poema sem a necessidade de entender a sua linearidade, uma vez que, os versos se complementam de forma solta e irregular, além das condições de se construir, no inicio do século XX, a imagem de uma mulher independente ou idealizada por uma sociedade dita moderna. Há a probabilidade de que o pseudônimo de Lívio seja para esconder um eu lírico feminino, como nas publicações das Cantigas de Amigo do Trovadorismo, uma vez que, Lívio pode ser o pseudônimo da escritora desses poemas publicados na página dois, na coluna Cosmorama.

O ano de 1935 é também rico de poemas, crônicas e contos de autores que tiveram projeção na região mas, não continuaram uma carreira literária. Além de poemas de versos livres, também são publicados inúmeros sonetos de Clarêncio Baracho nessa coluna, o que nos levar a crer que os textos poéticos, seja em forma de poemas de forma livre ou tradicional, têm uma maior divulgação nessa coluna. Seja o caso do seguinte soneto:

\author{
O urubu \\ Eil-o... só, afinal, nos restos de uma ossada. \\ Alquebrado o urubu, velho, triste e indolente, \\ Outrora vencedor do espaço, heril, fremente \\ Rasgando o céu azul num vôo* de alvorada. \\ Em dias de calor olhava indiferente \\ O mundo, no apogeu da altura ilimitada \\ Senhor do firmamento em rutila jornada \\ Descia como um Rei, magestoso* e imponente. \\ Ai de mim! Eu que ausculto os corações humanos \\ Vi o urubu sem mais a intrepidez radiosa \\ Das azas*, a tombar, vencido pelos anos... \\ E como ele também muita gente há no mundo \\ Que depois de viver em ascenção* gloriosa \\ Sem pão, arqueja, só, num frio catre immundo*! \\ (DIÁRIO n. 2.287 de 06/03/1935, p. 3)
}

Aos observarmos os versos do soneto de Clarêncio nos é possível identificar a riqueza de palavras que ele usa, sendo que, algumas delas nem são mais usadas na modernidade, como "heril", "fremente", mas que soavam, para o inicio do século XX, como sinônimo de cultura. Também é possível observar que, além de manter a forma do poema,

\footnotetext{
${ }^{4}$ Os asteriscos indicam que as palavras eram grafadas dessa forma.
} 
com as rimas alternadas no final das estrofes, e a construção da imagem nos leva a longos voos, viagens e possiblidade de comparação entre os processos da alma humana e de suas características e condições sociais de forma atemporal, pois o homem que alcança o poder continua o mesmo cheio de vontades e glórias, muitas vezes submetendo os de menor poder econômico, cultural ou social a ultrajes e humilhações. Trata-se, enfim, um dia, este mesmo homem pode da supressão do poder, seja pelas imprecisões da vida, seja pela perda da juventude. Muito provavelmente, ressoam no texto os influxos de leituras baudelairianas, especialmente aqueles advindos do clássico poema "O albatroz" (As flores do mal, 1857) .

No Diário da Tarde, as publicações variam de dias, mas, a preferência é pela segunda-feira, pois o jornal só tinha publicações até os dias de sábado. Essa preferência por publicações, especialmente, às segundas-feiras se dá pela busca dos leitores da região, que tinham no jornal uma fonte de informação importante, sobre os acontecimentos do Brasil e do mundo. Atrelada a essa busca e necessidade de informação vêm às publicações literárias das colunas já citadas, quase sempre na página dois ou quatro, pois raro são os dias em que essas publicações aparecem em outras páginas.

Como bem salientou Silviano Santiago (1993) em seu artigo sobre a crítica literária nos jornais:

\begin{abstract}
A literatura através dos contos, poemas, ensaios e crítica passou a ser esse algo mais que fortalece semanalmente os jornais através de matérias de peso, imaginativas, opinativas, críticas, tentando motivar o leitor apressado dos dias da semana a preencher o lazer do weekend de maneira inteligente. (SANTIAGO, 1993a, p. 14).
\end{abstract}

Apesar de no início do século haver um grande número de pessoas que escreviam nos jornais e, muitos deles eram médicos, advogados, comerciantes e bem poucos jornalistas de profissão, há alguns que são fixos dos cadernos e colunas literários e, mesmo sendo colaboradores do jornal, participavam de outros veículos da imprensa. Nessas publicações literárias também estão presentes os intelectuais, no mais amplo sentido da palavra, pois eram professores, universitários, acadêmicos, escritores, cientistas sociais, filósofos, psicanalistas, artistas e até políticos.

As publicações referidas, do Diário da Tarde, ocorreram no contexto literário do que se convencionou denominar de "romance de 30 " no Nordeste ${ }^{6}$, ou seja, uma época que ficou marcada, na história da literatura, por uma visão crítica acerca da realidade do país e suas crises sociais. Sendo assim, é de se perguntar sobre as temáticas predominantes nas

\footnotetext{
${ }^{5}$ Sobre a recepção de Baudelaire no Brasil, cf. o estudo "Os primeiros baudelairianos”, de Antonio Candido (2000).

${ }^{6} \mathrm{Cf}$. a respeito o estudo Uma história do romance de 30, de Luís Bueno (2006).
} 
colaborações, independente dos gêneros nos quais elas ocorrem. Na pesquisa em andamento, tal ocorrência se manifesta, numericamente, em colaborações, nos mais diversos gêneros, não obstante a predominância da forma poemática, da crônica e do conto. Como uma manifestação periférica, a literatura local tem muito a revelar ainda sobre as repercussões do movimento modernista no seu imbricamento com movimentos regionais de representação literária e cultural, em proveito de uma visão mais complexa sobre o sistema literário que se consolidava naquele momento, segundo a leitura de Candido (1980).

\section{Referências}

As dores dos flagelados. Diário da Tarde, Ilhéus, p.1, 06 Abr. 1933.

BARACHO, Clarencio. O urubu. Diário da Tarde, Ilhéus, p. 3, 06 Mar. 1935.

BARBOSA, Socorro de Fátima Pacífico. Jornal e leitura: a imprensa brasileira no século XIX. Porto Alegre: Nova Prova, 2007.

BUENO, Luís. Uma história do romance de 30. São Paulo: Universidade de São Paulo; Campinas: Unicamp, 2006.

CANDIDO, Antonio. Os primeiros baudelairianos. In: outros ensaios. 3. ed. São Paulo: Ática, 2000. p. 23-38. . A educação pela noite e Literatura e cultura de 1900 a 1945. In: . Literatura e sociedade. 6. ed. Rio de Janeiro: Ed. Nacional, 1980. p. 109-138.

DERRIDA, Jacques. Mal de arquivo: uma impressão freudiana. Tradução Cláudia de Moraes Rego. Rio de Janeiro: Relume Dumará, 2001.

FOUCAULT, Michel. A arqueologia do saber. Tradução Luiz Felipe Baeta Neves. Rio de Janeiro: Forense Universitária, 2002.

LE GOFF, Jacques. História e memória. Tradução Bernardo Leitão, Campinas, SP: Editora da Unicamp, 1996.

LIVIO. Os meus versos de amor. Diário da Tarde, Ilhéus, p.4, 10 Jan. 1931. Sem título. Diário da Tarde, Ilhéus, p.4, 12 Jan. 1931. Uma perfeição. Diário da Tarde, Ilhéus, p.2, 07 Fev. 1931.

MEYER, Marlyse. Folhetim: uma história. São Paulo: Companhia das Letras, 1996.

NORA, Pierre. Entre memória e história. A problemática dos lugares. Projeto História. São Paulo, n. 10, p. 07-28, dez. 1993.

Pagé Tupiniquim. Possuída. Diário da Tarde, Ilhéus, p.4, 07 Abr. 1933. Kiss. Diário da Tarde, Ilhéus, p.4, 08 Abr. 1933. 
SANTIAGO, Silviano. Crítica literária e jornal na pós-modernidade. Aletria: Revista de Estudos de Literatura, Belo Horizonte, n. 1, p. 11-17, 1993.

THEODORO, Janice. Memória e esquecimento: nos limites da narrativa. Revista Tempo Brasileiro, Rio de Janeiro, n. 135, p. 61-73, 1998.

\section{Ilhéus Diary: the literary texts of the decade 30}

Abstract: At the beginning of the last century newspapers were the biggest promoters of Literature in Brazil, since the books were scarce, they cost very expensive and did not reach the peripheral regions of the country. Thus, there is the need to preserve the newspapers and periodicals of the early twentieth century, since these are not always preserved in a suitable and convenient manner. An exception to this reality are the newspapers of major centers such as Folha de São Paulo that has successful experiences about the preservation of literary publications in their old issues. On the other hand, newspapers like the Journal of Ilheus afternoon, that keep on their pages a rich historical and literary collection, are deteriorating for lack of space and adequate conservation, even though an important collection for the preservation of Literary Memory South Bahia.

Keywords: Newspapers. Journals. Literature. Memory. Diary.

Recebido: $28 / 10 / 2016$

Aceito: 05/05/2017

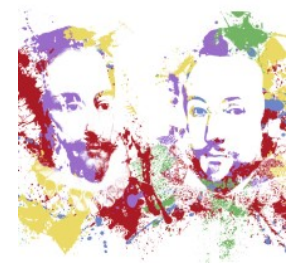

